This is an electronic reprint of the original article. This reprint may differ from the original in pagination and typographic detail.

Author(s): Kyppö, Anna; Natri, Teija; Pietarinen, Margarita; Saaristo, Pekka

Title: $\quad$ Use your languages! : From monolingual to multilingual interaction in a language class

Year: $\quad 2015$

Version:

Please cite the original version:

Kyppö, A., Natri, T., Pietarinen, M., \& Saaristo, P. (2015). Use your languages! : From monolingual to multilingual interaction in a language class. In J. Jalkanen, E. Jokinen, \& P. Taalas (Eds.), Voices of pedagogical development : expanding, enhancing and exploring higher education language learning (pp. 319-335). Research-publishing.net. https://doi.org/10.14705/rpnet.2015.000297

All material supplied via JYX is protected by copyright and other intellectual property rights, and duplication or sale of all or part of any of the repository collections is not permitted, except that material may be duplicated by you for your research use or educational purposes in electronic or print form. You must obtain permission for any other use. Electronic or print copies may not be offered, whether for sale or otherwise to anyone who is not an authorised user. 


\title{
1 Use your languages! From monolingual 1 to multilingual interaction in a language class
}

\author{
Anna Kyppö, Teija Natri, \\ Margarita Pietarinen and Pekka Saaristo ${ }^{1}$
}

Abstract

$\mathrm{T}$ his reflective paper presents a new course concept for multilingual interaction, which was piloted at the University of Jyväskylä Language Centre in the spring of 2014. The course, implemented as part of the centre's action research, is the result of a development process aimed at enhancing students' multilingual and multicultural academic communication competences along with promoting use of their entire linguistic repertoire. The course concept was inspired by the EU project Modularising Multilingual and Multicultural Academic Communication Competence (MAGICC), whose main intent is "to integrate multilingual and multicultural academic communication competences as graduate learning outcomes at [the] BA and MA level” (http://www.unil.ch/magicc/home/menuinst/objectifs.html). The main focus of the pilot course was on teachers' approach to multilingual teaching, teachers' interaction with each other and with students as well as students' approach to communication in a simulated multilingual and multicultural environment. Students' employment of their entire linguistic repertoire resulted in an evident increase of their intercultural awareness, enhancement of their intercultural communication competences and of their skills in mediating information in multilingual and multicultural contexts.

Keywords: multilingual interaction, multicultural communication, multilingual multicultural academic communication competence, intercultural awareness.

\footnotetext{
1. Language Centre, University of Jyväskylä, Finland; anna.kyppo@jyu.fi; teija.natri@jyu.fi; margarita.pietarinen@jyu.fi; pekka.c.saaristo@jyu.fi

How to cite this chapter: Kyppö, A., Natri, T., Pietarinen, M., \& Saaristo, P. (2015). Use your languages! From monolingual to multilingual interaction in a language class. In J. Jalkanen, E. Jokinen, \& P. Taalas (Eds), Voices of pedagogical development Expanding, enhancing and exploring higher education language learning (pp. 319-335). Dublin: Research-publishing.net. doi:10.14705/rpnet.2015.000297
} 


\section{Introduction}

This study introduces a pilot course aimed at the enhancement of students' skills in multilingual and multicultural communication. The course Multilingual Interaction: Use Your Languages was offered by the University of Jyväskylä Language Centre in the spring of 2014. Teachers' interest in multilingual and multicultural issues and a concern for the increase of multilingualism and multiculturalism in workplace communication were important motivations for implementing such a course. However, the project Modularising Multilingual and Multicultural Academic Communication Competence for BA and MA levels (MAGICC 2011-2014; see Natri \& Räsänen in this volume) served as a major source of inspiration. The project is part of the European Union Lifelong Learning Programme and aims to conceptualise multilingual and multicultural communication competences for higher education and thus to complement the Council of Europe's Common European Framework of Reference for Languages. The MAGICC project emphasises the role of languages and communication as part of academic expertise. The project, in the underlying principles and concepts of its conceptual framework, says that multilingual and multicultural academic communication competence

"is an individual's communicative and interactive repertoire, made up of several languages and language varieties including first language(s) at different levels of proficiency, and various types of competence, which are all interrelated. The repertoire in its entirety represents a resource enabling action in diverse use situations. It evolves across time and experience throughout life, and includes growth in intercultural awareness and ability to cope with, and participate in, multicultural contexts of academic study and working life" (Räsänen, Natri \& Foster Vosicki 2013: 5).

The pilot course was implemented as part of the Language Centre's institutional action research. The main focus was on the development of multilingual and multicultural competences, which involve not only a good command of an individual's L1 and L2, but also efficient use of one's overall language repertoire, that is, one's partial competences in various languages. When competences are 
perceived in this way, successful multilingual communication means, first of all, the abilities to switch and mediate from one language to another as well as to use one or more languages for the purpose of retrieving, managing, conceptualising and communicating the information in another language. Furthermore, multicultural communication and interaction foregrounds negotiations of meanings, attitudes towards otherness, tolerance of ambiguity and an awareness of multicultural settings.

\section{Context of the study}

This section introduces the concepts that supported the development and implementation of the course. A brief introduction of translanguaging and transculturation is followed by a presentation of the course's main objectives: raising the awareness of multilingual and multicultural communication and the development of multilingual competence. Culture, competence and communication, which form the main conceptual threads of the course, are in focus.

In the field of applied linguistics, the concepts of translanguaging and transculturation (Garcia 2009; Garcia \& Sylvan 2011; Lewis, Jones \& Baker 2012a, 2012b) are known as dynamic processes that involve meaning-making and knowledge-shaping through language and thus learning the language (Swain \& Watanabe 2012). When two or more languages are systematically combined within the same learning activity, translanguaging may contribute to using one's linguistic repertoire more freely and flexibly, as well as to creating a social space for speakers through their personal histories and experiences, so that they can benefit from mediating and meaning-making across languages (Park 2013). From this perspective, multilingualism is perceived as a complex of specific semiotic resources and a repertoire of varying language abilities rather than as collections of separate languages (see Blommaert 2010).

One of the main objectives of the pilot course was to help students become aware of the factors that may affect multilingual and multicultural communication, and 
through that to develop their skills and competences for successful participation in such contexts. This involves the readiness to make use of one's own linguistic repertoire by, for example, switching fluently from one language to another or by mediating messages between the interactants who are otherwise unable to understand each other. In order to encourage the students to reflect on various contextual and attitudinal factors which affect different communicative events and circumstances, the concepts of language, culture and communication as well as some specific features influencing multicultural communication were introduced at the beginning of the course. Moreover, some fundamental views from sociolinguistics and the sociology of language, intercultural pragmatics, communication studies and different social sciences were also presented.

The concept of culture given in the course was in line with Spencer-Oatey's (2009: 3) definition, which views culture as "a fuzzy set of basic assumptions and values, orientations to life, beliefs, policies, procedures and behavioural conventions $[\ldots]$ shared by a group of people, [which] influence (but do not determine) each member's behaviour and his/her interpretations of the 'meaning' of other people's behaviour". The concept of communicative competence was based on Figueroa's (1994: 65) idea that an individual's competence means being able "to judge the consequences of actions, to plan strategies, to have expectations as to what is supposed to happen or what might happen or what is expected, in short, to make sense of the situation and act accordingly". Finally, the concept of communication was viewed as a cooperative and interactive process where the meanings are constructed and negotiated within different sociohistorical and cultural circumstances. It is more than transforming the propositional information concerning the state of affairs of external objects. As Mey (2001: 10) claims, “messages are not just 'signals', relayed through impersonal channels; the human expression functions as an appeal to other users and as means of social togetherness".

Among other issues related to the functions and implementation of communication, the inevitability of communication was also discussed. As Watzlawick, Beavin Bavelas \& Jackson (1967) point out, making an effort to avoid communication is also a form of communication. Practical issues 
arising from this aspect are related to such modalities as clothing, nonlinguistic gestures or silence as a resource for the construction of meaning or as a communicative practice.

Students were also briefly introduced to some traditional and frequently discussed issues present in the intercultural communication studies, such as the concept of politeness and face, addressivity, self-presentation, conflict management practices, directness/indirectness, stylistic aspects and the use and tolerance of silence in interaction (for more on these issues, see Brown \& Levinson 1978, 1987; Goffman 1972; Gudykunst \& Ting-Toomey 1988; Nakane 2007; Sajavaara \& Lehtonen 1997; Ting-Toomey 1988; Ting-Toomey \& Kurogi 1998; Ting-Toomey \& Oetzel 2003).

Finally, the spectrum of communicative competences was explored as semiotic wholes or aggregates which may facilitate communication in multilingual situations when one or more languages are used. From the viewpoint of pragmatics, specific and individual competences referring to the dynamic capacity to carry out different kinds of communicative acts in different circumstances were introduced. An individual's overall linguistic competence is to be perceived as a facilitator rather than as a barrier to interpersonal communication (e.g. fear of imperfectness, shortcomings in languages).

\section{Course information}

This section provides basic demographics and information about the content, modes and expected outcomes of the course.

\subsection{Course demographics}

Out of 19 students, 14 were Finnish including one Swedish-Finnish bilingual. Russia, Kazakhstan, Greece, the Czech Republic and Macedonia were represented by one student each. Most of the participants were degree students in the humanities, mainly in linguistics, journalism, communication, history 
and art education. The disciplines of special education, IT, business and economics were also represented.

In addition to a participant's mother tongue, partial competence in at least two languages was expected, but no language pre-tests were required. The students' levels of language proficiency were instead based on self-assessments. All students spoke at least two languages in addition to their mother tongue; in the case of the Finnish students, even three additional languages were spoken. Interestingly, English was not the strongest language for all the Finnish students, with some assessing their English competence as poor. The group's linguistic repertoire (receptive skills) was as follows: English (17), Finnish (15), Swedish (10), Spanish (10), German (9), French (8), Russian (8), Slovak (4), Italian (4), Danish (2), Norwegian (2), Finnish sign language (2), Portuguese (2), Chinese (2) and furthermore, Czech, Greek, Japanese, Kazakh, Macedonian, Polish, Serbian, Cantonese and Swiss German (one speaker per language).

\subsection{Expected learning outcomes}

Students were expected to participate in multilingual communication, that is, to effectively employ their own linguistic repertoire. As could be expected, most of them showed genuine interest in languages and cultures and welcomed the opportunity to practice their multilingual agility ${ }^{2}$.

Apart from the opportunity to use multiple languages, the focus was also on the development of their cultural awareness, in other words, on understanding the impact of culture on overall communication and interaction, including the interpretation and mediation of information and analysing one's own communication from a cultural perspective. Students were also expected to specify their personal learning needs.

2. Teachers and students shared a positive view and ideology towards multilingualism and multiculturalism, which is not uncommon among sociolinguists and language teachers. Regarding negative effects, ineffectiveness has been mentioned as one example. However, multilingualism is not viewed as positive in all political-institutional contexts (cf. Blommaert, Leppänen. \& Spotti 2012; Lo Bianco 2004). 


\subsection{Course curriculum and schedule}

The course was offered in four- to six-hour weekly contact sessions. In addition, the web-based learning platform Optima was used for various out-of-class activities and course interaction as well as for sharing course resources such as students' personal folders and learner logs, the course schedule and programme.

The focus of every session was on different aspects of multilingual and multicultural communication. After getting familiar with the course content, course participants introduced themselves in various languages. To get familiar with the basic concepts of multilingualism and multiculturalism, a lecture on the fundamental insights into language use, culture and communication was offered.

The purpose of the introductory theoretical background and key concepts was to establish some grounds and tools for reflection and further discussions. The purpose was not only to raise students' awareness of these issues during the course, but also to be able to link them with their personal communication experiences, recognising some of the factors as dominant.

Course participants shared their personal experiences of intercultural communication, such as their knowledge of the world and culture-bound cues of nonverbal communication, such as extralingual elements, body-language and gestures. To demonstrate these concepts, excerpts from two films were used. While the language spoken in the first film was not understood at all, the second film offered a peaceful coexistence of three people who did not share a common language, yet still managed to reach a mutual understanding. Further topics were related to intercomprehension and mediation as well as to cultural barriers in the use of advertisements. In this context, mediation means transferring information from one language to another. Furthermore, intercomprehension is related to multilingual reading: reading texts written in languages that the learners might not have learned but which are genetically or typologically related to the languages in their plurilingual repertoire, be it their mother tongues or foreign and second languages (Lenz \& Berthele 2010). 
In compliance with the MAGICC project, students performed simulated multilingual and multicultural negotiations. Persuasive argumentation in multilingual circumstances was practised in the form of persuasive talks aimed at selling an idea, service or product to the appropriate audience. To support their claims, presenters were expected to use languages other than the language of presentation and answer the clients' questions or to provide further information in multiple languages. Finally, the topics of the final session were related to the cultural issues in decision-making and multilingual storytelling. Small groups were appointed to work on a simulation aimed at selecting a new company manager. Candidates' multicultural profiles made the choice difficult. As a matter of fact, every group made a different choice and used different reasons to justify its choice.

In multilingual storytelling, a short story was told in groups consisting of five students. The first student read the story and retold it to the next student in another language, who again retold the story to the next one in a different language and so on. Finally, the last version of the story was compared with the original one. The course was concluded with students' reflections on various perspectives of multilingual and multicultural communication. Before each upcoming session, students were expected to reflect on the issues related to the previous session in their learner logs. The purpose of learner logs was to help students follow their learning process and, through this reflection, enhance their multicultural and multilingual awareness.

\subsection{The teacher team}

Five language teachers and one researcher interested in the multilingual and multicultural issues participated in the pilot. The teachers' strong languages were English, Finnish, French, Russian, Slovak, Spanish and Swedish. Four to five teachers were present at all of the sessions. Despite continuous use of several languages at one time, written instructions were given in English, because English was evidently the participants' lingua franca. Oral instructions, however, were given in languages other than English. In order to inspire the students to activate their entire linguistic repertoire, teachers also shared their 
own personal linguistic repertoires, including their partial and elementary competences. In compliance with the requirements for students, they attempted to use their weaker languages in both the contact and online communication. Incidental mismatches in the repertoires were regarded as enriching grounds for applying the mediation and intercomprehension strategies between the students and teachers.

In traditional teaching contexts, lesson preparation as well as classroom control and management is the responsibility of a single teacher. In team teaching, however, a group of teachers carries the responsibility for the whole teaching process: planning, teaching, evaluating learning activities and so on. Effective team teaching requires more than the space and time spent together; it also necessitates a change of mindset and teaching practices. Moreover, flexibility and the need to acknowledge the participation and interference of other colleagues are crucial. In our case, multilingual team teaching conducted by teachers of different languages was perceived as an authentic multicultural task demanding mutual tolerance and respect of otherness. Teacher cooperation was to a great extent based on continuous negotiation, which is a typical characteristic of intercultural interaction. Both students and teachers had to acknowledge their own culture-embedded values and conventions, be willing to understand the communicative difficulties that may arise in a particular intercultural context, and constructively deal with them.

\section{Reflections and course evaluation}

This section offers some reflections from the students as well as the teachers about the course, an evaluation of the course and some implications for the future.

\subsection{Student reflections}

During the course, students were expected to reflect on their understanding of multilingualism and multicultural interaction. Reflections were related to the 
topics discussed during the sessions and how they were related to students' previously acquired competences, new ideas that emerged during the sessions, or perceptions on what was learned and what students considered to be interesting or insightful. The comments and student voices below are extracted from the students' learner logs and feedback.

Students boldly involved themselves in various multilingual situations. In the learner logs, they clearly indicated the motivation and the need to employ their entire language repertoire:

"I loved the idea of changing the language every time and although it was by no means easy, it was just the sort of mental challenge that I enjoy. The task also made me re-evaluate some of my language skills".

Participation in the course for the reason of improving one's language skills and identifying the already existing competences was one of the learning goals. The activation of weaker languages, even acquiring some partial competence in new languages, seemed to be a prevailing reason for participating in the course. Nevertheless, at the same time the weaker languages were perceived to be difficult:

"The second task was to summarise an article in one of the weaker languages one knows. I tried to explain this really short text about French midwives being on strike, but it turned out to be really hard. Maybe the fact that the people in my group didn't speak French also affected the situation, but I was still pretty stiff with my explanations. It was a really educational moment: This happens when you don't use your languages".

Multicultural issues made the students reflect on the multicultural competences and their importance in communication:

"Communication is a complex phenomenon and all communication takes place in a specific context and under the influence of a culture. 
I think that culture creates a frame for almost all we do and especially for communication. Our culture affects communication together with our individual characteristics. One can either emphasise the individual view or the environmental one, but they are both always present. I think our discussion about genes and whether all kinds of communication knowledge can be learned or not, was very interesting".

Multilingualism was not perceived only as the use of one or more languages, but also as a matter of knowing the culture and history as well the social and political situation of a country. It was further seen as acknowledging the other participants, their ethnicity, gender, educational background and other various situational, circumstantial and interpersonal factors which affect the process of communication. Students considered contextualisation to be important, seeing it as, on the one hand, taking historical, social, political, economic and other contexts into account and, on the other, the use of the language (e.g. the type of the language, language proficiency, language policy). Personal experience of various communication situations was also mentioned.

Multilingualism as a result of growing international mobility was mentioned by several course participants. For example, according to one student, multilingualism was equal to speaking a foreign language fluently, "almost as a native speaker". Only after spending some time in a foreign country did the student realise that multilingualism was the sum of various skills and language proficiency, that is, that "speaking a foreign language perfectly" was only a minor part of the whole:

"Sometimes, when we use certain words in one language, the same words may mean something else in another language. We should understand the whole situation and not the specific words..."

For the non-Finnish course participants, the Finnish-Swedish and FinnishRussian bilingualism, which is present in Finland as a result of a fairly large population of Finland Swedes and Russian-speaking people, became a source of admiration and sincere interest leading to the re-evaluation of their own 
concept of multilingualism. The concepts of directness and indirectness in communication, that is, conveying messages by words as well as by other means of communication (e.g. non-verbal communication, body language, and mimicking) were perceived as crucial factors that clearly facilitate interaction.

The awareness of being, or rather, becoming multicultural and multilingual, as well as the intermingling of linguistic identities, was also addressed by the students. Speaking different languages at different levels, in various contexts, was occasionally experienced as "becoming someone else". Living in another country was mentioned as a good opportunity to become multilingual and multicultural. Revealing one's linguistic and cultural background is often related to the issue of self-identification. For example, a person can have a multilingual and multicultural identity, even in case of a monolingual and culturally homogenous background.

One student writing an MA thesis on multilingualism and multiculturalism wondered what language actually is, considering that it might be only one of many tools for communication. For example, using English as a lingua franca in interaction with international friends does not reflect the real English culture, rather, it is only a tool of communication. Nevertheless, the interaction may subconsciously reflect English culture as well, because language and culture "always go hand in hand". Similar issues were raised in relation to the degree of language proficiency. One student even wondered if people could be monolingual and monocultural ${ }^{3}$.

The concepts of multilingualism and multicultural communication, that is, communication across different cultures, seem best described as the communication between people who come from different cultural backgrounds and search for a mutually understandable way of interaction through negotiating meanings.

3. In a strict sense, the answer seems to be no (see Canagarajah 2011b). Nevertheless, on a subjective level, individuals may consider themselves to be monocultural. See Pitkänen-Huhta and Hujo (2012) for a discussion about an older couple of monolingual Finnish adults. 


\subsection{Teacher reflections and implications}

Due to the multilingual and multicultural nature of this team teaching, the teachers, like the students, also reflected on the process of preparing and implementing the course as well as on the various stages of conducting the course. Teachers' collaborative teaching included a thorough, time-consuming stage of planning and preparation. The opinions and views of the researcher involved in the process were a great contribution to the teamwork as well. On a personal level, the preparation of course activities and teaching itself was highly creative, generating multiple ideas for future course projects. To demonstrate this creative process, some excerpts of the teachers' reflections are presented below:

"Participating in the course teaching team has been a thrilling experience.

Despite an excessive workload, I kept looking forward to the upcoming teaching session. I spent a lot time on the preparation of my teaching and did my best to employ all my knowledge and skills on this course. Nevertheless, there are some areas of teaching that might be improved, for example, the activation of students' offline interaction, communication through social media, blog writing or chats".

"This course offered me completely new insights into teaching the less commonly taught languages. Instead of a general lack of commitment to learning some less commonly spoken, so-called smaller languages, learners' (and teachers') attention should rather be turned to the employment of their overall language repertoire. For example, speakers of some Slavic languages may acquire the passive knowledge of some other Slavic languages due to the mutual intelligibility of Slavic languages and thus get interested in a particular language. The same may be applied to other language groups, such as the Romance and Germanic languages".

The pedagogy of less commonly taught languages (LCTL) emerged in relation to the mutual intelligibility within language groups, such as the mutual intelligibility of languages in the Slavic or Romance language family: 
"I got the impression that quite a few students were wavering between the more traditional goals, viewing the course as an instrument to improve the skills of the languages they already knew, and the way of identifying their already existing competences as a practical tool of communication".

\section{Concluding remarks}

The Use Your Languages course was a teaching experiment focused on enhancing students' multilingual and multicultural communication and activating their linguistic repertoire. We feel that this course objective was reached, even though not all students believed that they had enhanced their communication skills in the weaker languages. Nonetheless, they acquired some new insights into multilingual communication and clearly enriched their linguistic repertoire. Unlike in more traditional language instruction, the main focus was not on the correctness of language but on agency, that is, on what the learners could do with their existing language competences. Students also recognised the importance of acknowledging and adapting to various multicultural communication situations.

As for the teachers' perspective, the course was perceived as a challenge due to the excessive workload, especially in the preparation and planning of the teamteaching approach. However, it was also an enriching teaching experience. The teachers became students and proceeded through the same stages of employing their entire linguistic repertoire in teaching situations. Thus the course enhanced the teachers' multilingual and multicultural communication and activated their linguistic repertoire. The stage aimed at preparation of learning activities was perceived as a highly creative process, one that, together with the positive atmosphere within the teacher team, contributed to the successful implementation of the pilot course.

In the future, the course may be implemented in more personal learning environments and include, for example, extended use of social media and multimodal interactive online resources. We believe that personal learning 
environments may contribute to the increase of learners' multilingual and multicultural awareness. Furthermore, simultaneous use of many languages, referred to as, among many other terms, code meshing (for more, see Canagarajah 2011b; Lewis et al. 2012a, 2012b)4, where the languages used are "a part of a single integrated system" (Canagarajah 2011a: 403), may result in distinguishing students' competencies as semiotic wholes, what in the end, may reduce the traditional compartmentalisation of languages. This perspective could also demystify multicultural communication as it compares to monocultural communication. With this mindset, the most challenging task for language teachers will be to find the balance between accurate language use (e.g. in writing) and effective language use in terms of communication and interaction.

\section{References}

Blommaert, J. 2010. The sociolinguistics of globalization. Cambridge: Cambridge University Press. doi:10.1017/CBO9780511845307

Blommaert, J., Leppänen, S. \& Spotti, M. 2012. Endangering multilingualism. In J. Blommaert, S. Leppänen, P. Pahta \& T. Räisänen (eds.), Dangerous Multilingualism. Northern Perspectives on Order, Purity and Normality. Houndmills, Basingstoke: Palgrave Macmillan, 1-21. doi:10.1057/9781137283566.0006

Brown, P. \& Levinson, S. 1978. Universals in language use: politeness phenomenon. In E.

Goody (ed.), Questions and Politeness: Strategies in Social Interaction. Cambridge: Cambridge University Press, 56-311

Brown, P. \& Levinson, S. 1987. Politeness: some universals in language use. Cambridge: Cambridge University Press.

Canagarajah, A. S. 2011a. Codemeshing in academic writing: identifying teachable strategies of translanguaging. The Modern Language Journal, 95 (3), 401-416. doi:10.1111/j.1540-

\footnotetext{
4. An example of the concepts expressing the same or almost the same meanings used within different frameworks. Other related terms used in the literature are metrolingualism, polylanguaging, polylingual languaging, heteroglossia, heterography, translingual practice, flexible/dynamic/holistic bilingualism, multilanguaging, hybrid language practices, pluriliteracy, transcultural literacy/ writing, multiliteracies, continua of biliteracy, fluid lects (Cf. Canagarajah 2011b: 2; Lewis et al. 2012a: 650; 2012b: 655-656).
} 
Canagarajah, A. S. 2011b. Translanguaging in the classroom: emerging issues for research and pedagogy. In L. Wei (ed.), Applied Linguistics Review 2. Berlin: De Gruyter Mouton, 1-28. doi:10.1515/9783110239331.1

Figueroa, E. 1994. Sociolinguistic metatheory. Oxford: Pergamon.

Garcia, O. 2009. Bilingual education in the 21st century: a global perspective. Oxford, UK: Wiley-Blackwell.

Garcia, O. \& Sylvan, C. 2011. Pedagogies and practices in multilingual classrooms: singularities in pluralities. The Modern Language Journal, 95 (3), 385-400. doi:10.111/ j.1540-4781.2011.01208.x

Goffman, E. 1972. Interaction ritual: essays on face-to-face behavior. London: Allen Lane / The Penguin Press.

Gudykunst, W. \& Ting-Toomey, S. 1988. Culture and interpersonal communication. Newbury Park: Sage Publications

Lenz, P. \& Berthele, R. 2010. Assessment in plurilingual and intercultural education - Satellite Study $N^{\circ}$ 2. Guide for the development and implementation of curricula for plurilingual and intercultural education. Geneva: Council of Europe, Language Policy Division. Retrieved from http://www.coe.int/t/dg4/linguistic/Source/Source2010_ForumGeneva/ Assessment2010_Lenz_EN.pdf

Lewis, G., Jones, B. \& Baker, C. 2012a. Translanguaging: origins and development from school to street and beyond. Educational Research and Evaluation, 18 (7), 641-654. doi: 10.1080/13803611.2012.718488

Lewis, G., Jones, B. \& Baker, C. 2012b. Translanguaging: developing its conceptualisation and contextualisation. Educational Research and Evaluation, 18 (7), 655-670. doi:10.10 80/13803611.2012.718490

Lo Bianco, J. 2004. Language planning as applied linguistics. In A. Davies \& C. Elder (eds.), The Handbook of Applied Linguistics. Malden: Blackwell Publishing, 738-762. doi:10.1002/9780470757000.ch30

Mey, J. 2001. Pragmatics. An Introduction. Oxford: Blackwell Publishers.

Nakane, I. 2007. Silence in intercultural communication. Perceptions and performance. Amsterdam: John Benjamins Publishing Company. doi:10.1075/pbns.166

Natri, T. \& Räsänen, A. 2015. Developing a conceptual framework: the case of MAGICC. In J. Jalkanen, E. Jokinen \& P. Taalas (eds), Voices of Pedagogical Development - Expanding, Enhancing and Exploring Higher Education Language Learning. Dublin: Researchpublishing.net, 85-102. doi:10.14705/rpnet.2015.000288 
Park, M. S. 2013. Code-switching and translanguaging: potential functions in multilingual classrooms. Working Papers in TESOL \& Applied Linguistics, 13 (2), 50-52.

Pitkänen-Huhta, A. \& Hujo, M. 2012. Experiencing multilingualism - the elderly becoming marginalized? In J. Blommaert, S. Leppänen, P. Pahta \& T. Räisänen (eds.), Dangerous Multilingualism. Northern Perspectives on Order, Purity and Normality. Houndmills, Basingstoke: Palgrave Macmillan, 261-283. doi:10.1057/9781137283566.0020

Räsänen, A., Natri, T. \& Foster Vosicki, B. 2013. MAGGICC conceptual framework. Lifelong Learnign Programme. Retrieved from http://www.unil.ch/files/live//sites/magicc/files/ shared/Revised_Conceptual_Framework_MAGICC.pdf

Sajavaara, K. \& Lehtonen, J. 1997. The Silent Finn revisited. In A. Jaworski (ed.), Silence. Interdisciplinary Perspectives. Berlin: Mouton de Gruyter, 263-283.

Spencer-Oatey, H. 2009. Introduction. In H. Spencer-Oatey (ed.), Culturally Speaking. Culture, Communication and Politeness Theory. London: Continuum, 1-8.

Swain, M. \& Watanabe, Y. 2012. Languaging: collaborative dialogue as a source of second language learning. In C. Chapelle (Ed.), The encyclopedia of applied linguistics. Oxford: Blackwell Publishing. doi:10.1002/9781405198431.wbea10664

Ting-Toomey, S. 1988. A face-negotiation theory. In Y. Kim \& W. Gudykunst (eds.), Theory in Intercultural Communication. Newbury Park: Sage, 213-235.

Ting-Toomey, S. \& Kurogi, A. 1998. Facework competence in intercultural conflict: an updated face-negotiation theory. International Journal of Intercultural Relations, 22 (2), 187-225. doi:10.1016/S0147-1767(98)00004-2

Ting-Toomey, S. \& Oetzel, J. 2003. Cross-cultural face concerns and conflict style. Current status and future directions. In W. Gudykunst (ed.), Cross-Cultural and Intercultural Communication. Thousand Oaks: Sage Publications, 127-147.

Watzlawick, P., Beavin Bavelas, J. \& Jackson, D. D. 1967. Pragmatics of human communication. A study of interactional patterns, pathologies, and paradoxes. New York: Norton. 


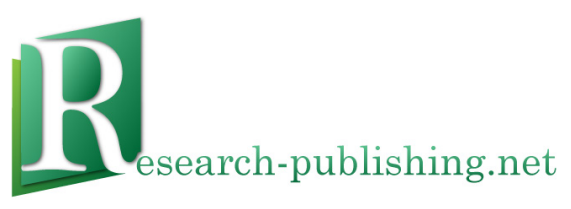

Published by Research-publishing.net, not-for-profit association Dublin, Ireland; Voillans, France, info@research-publishing.net

(C) 2015 by Research-publishing.net (collective work)

Each author retains their own copyright

Voices of pedagogical development - Expanding, enhancing and exploring higher education language learning Edited by Juha Jalkanen, Elina Jokinen, \& Peppi Taalas

Rights: All articles in this collection are published under the Attribution-NonCommercial -NoDerivatives 4.0 International (CC BY-NC-ND 4.0) licence. Under this licence, the contents are freely available online (as PDF files) for anybody to read, download, copy, and redistribute provided that the author(s), editorial team, and publisher are properly cited. Commercial use and derivative works are, however, not permitted.

\section{()ㅛ $\Theta \Theta$}

Disclaimer: Research-publishing.net does not take any responsibility for the content of the pages written by the authors of this book. The authors have recognised that the work described was not published before, or that it is not under consideration for publication elsewhere. While the information in this book are believed to be true and accurate on the date of its going to press, neither the editorial team, nor the publisher can accept any legal responsibility for any errors or omissions that may be made. The publisher makes no warranty, expressed or implied, with respect to the material contained herein. While Research-publishing.net is committed to publishing works of integrity, the words are the authors' alone.

Trademark notice: Product or corporate names may be trademarks or registered trademarks, and are used only for identification and explanation without intent to infringe.

Copyrighted material: Every effort has been made by the editorial team to trace copyright holders and to obtain their permission for the use of copyrighted material in this book. In the event of errors or omissions, please notify the publisher of any corrections that will need to be incorporated in future editions of this book.

Typeset by Research-publishing.net

Cover design by (C) Antti Myöhänen

ISBN13: 978-1-908416-25-4 (Paperback - Print on demand, black and white)

Print on demand technology is a high-quality, innovative and ecological printing method, with which the book is never 'out of stock' or 'out of print'.

ISBN13: 978-1-908416-26-1 (Ebook, PDF, colour)

ISBN13: 978-1-908416-27-8 (Ebook, EPUB, colour)

Legal deposit, Ireland: The National Library of Ireland, The Library of Trinity College, The Library of the University of Limerick, The Library of Dublin City University, The Library of NUI Cork, The Library of NUI Maynooth, The Library of University College Dublin, The Library of NUI Galway.

Legal deposit, United Kingdom: The British Library.

British Library Cataloguing-in-Publication Data.

A cataloguing record for this book is available from the British Library.

Legal deposit, France: Bibliothèque Nationale de France - Dépôt légal: septembre 2015. 